\title{
Article \\ Effects of Air Route Alternation and Display Design on an Operator's Situation Awareness, Task Performance and Mental Workload in Simulated Flight Tasks
}

\author{
Hao Chen ${ }^{1}\left(\mathbb{D}\right.$, Liping Pang ${ }^{1}$, Xiaoru Wanyan ${ }^{1, *}$, Shuang Liu ${ }^{1}$, Yufeng Fang ${ }^{1,2}$ and Da Tao ${ }^{3}(\mathbb{D}$ \\ 1 School of Aeronautic Science and Engineering, Beihang University, Beijing 100191, China; \\ beihangchenhao@buaa.edu.cn (H.C.); pangliping@buaa.edu.cn (L.P.); liushuangbh@buaa.edu.cn (S.L.); \\ buaa_ergonomics@163.com (Y.F.) \\ 2 Aviation Industry Corporation of China, Ltd., Beijing 100028, China \\ 3 Institute of Human Factors and Ergonomics, Shenzhen University, Shenzhen 518060, China; \\ taoda@szu.edu.cn \\ * Correspondence: wanyanxiaoru@buaa.edu.cn; Tel.: +86-132-6026-9679
}

Citation: Chen, H.; Pang, L.;

Wanyan, X.; Liu, S.; Fang, Y.; Tao, D.

Effects of Air Route Alternation and Display Design on an Operator's Situation Awareness, Task Performance and Mental Workload in Simulated Flight Tasks. Appl. Sci. 2021, 11, 5745. https://doi.org/10.3390/app11125745

Academic Editor: Rosario Pecora

Received: 17 May 2021

Accepted: 18 June 2021

Published: 21 June 2021

Publisher's Note: MDPI stays neutral with regard to jurisdictional claims in published maps and institutional affiliations.

Copyright: (c) 2021 by the authors. Licensee MDPI, Basel, Switzerland. This article is an open access article distributed under the terms and conditions of the Creative Commons Attribution (CC BY) license (https:// creativecommons.org/licenses/by/ $4.0 /)$.
Featured Application: A potential application of this work is to provide a theoretical basis and experimental data for the principles of improving a pilot's task performance and adaptive display design under the conditions of critical situations, such as air route alternation.

\begin{abstract}
Air route alternation caused by unexpected events in abnormal or emergency situations often produces adverse consequences on an operator's cognition and behavior in flight tasks. Under such a circumstance, it is especially necessary to examine the utility of the interaction displays usually designed based on the routine environment. This study was aimed to investigate the effects of air route alternation and display design on operators' situation awareness (SA), task performance and mental workload during simulated flight tasks. Twenty-four participants attended an experiment where they were instructed to perform simulated flight tasks with three types of display designs in both air-route-as-planned and air-route-altered conditions. Subjective measures, behavioral measures and eye movement measures were adopted to assess the participants' SA, task performance and mental workload. The results show that unexpected air route alternation increases mental workload as well as deteriorates the SA and task performance due to the gap between attention resource demand and supply. Reducing the demand of the operator's attention resource should be the focus when coping with unexpected events in abnormal situations. In addition, reasonable information layout, such as a center-layout design of the critical decision-making information, is more important than information salience for improving the SA and task performance in abnormal situations. Nevertheless, indicators with a high-salience design, such as a more open window design and immersive design, are still worth recommending.
\end{abstract}

Keywords: air route alternation; display design; situation awareness; task performance; mental workload; abnormal situation; unexpected events; aviation safety

\section{Introduction}

Situation awareness (SA), which refers to information perception, comprehension and projection [1], has long been considered as an important factor that influences flight safety in aviation [2]. It also has been widely recognized as a critical indicator of workplace safety $[3,4]$. Statistics showed that $70.8 \%$ of air accidents can be accounted for by human errors, $88.2 \%$ of which are related to SA [5,6]. The lack of or decrease in SA is likely to result in adverse consequences for flight safety, such as the occurrence of human errors, performance deterioration and even air accidents [7-9]. For instance, one of the main reasons for the Air France 447 crash in 2009 was the lack of SA during the pilots' communication [2,10-12]. SA can be a significant concern, especially in abnormal environments, 
where operators are required to respond immediately and appropriately to unexpected events or emergencies. In these scenarios, demands on the operators' SA can be even higher so that the operators' mental resources may not be able to provide sufficient support for good task performance, thereby leading to human errors [13-16].

There is a growing interest in examining the influence of unexpected events or emergencies in abnormal situations on operators' SA and other activities in the aviation and transportation fields. The literature has pointed out that operators do not always make appropriate responses to the unexpected events, such as air route alternation caused by inflight engine malfunction, air traffic disruption and in-flight medical emergencies, leading to a deterioration in system safety and reliability [17-21]. Different from routine working situations, workflows in abnormal situations would be interrupted or disrupted by unexpected events, and operators have to make a quick decision on whether to keep on the current workflows or perform an alternative one to address the unexpected events [21-23]. For example, when an in-flight medical emergency arises, pilots in cockpits need not only to seek medical support but also to cooperate with ground crews to evaluate the possibility of re-planning the air route. During this process, adequate SA is required for quick assessment, otherwise it may lead to delayed or risky decisions [24,25]. Pritchett et al. suggested that when a sudden emergency occurs, pilots need to formulate an appropriate list of alternative actions to handle the suspension or termination of the original flight plan, and it is necessary to support the pilot's situation assessment and decision making with planning aids $[10,15,16]$. Overall, the operators' SA tends to decline in workflows with unexpected changes, which probably lead to performance deterioration and even human errors $[16,26]$. Therefore, importance has been attached to decreasing the mental demands to maintain the operator's SA in abnormal situations [18-20].

A good interaction display design (i.e., what information to present and how to present the information) is also conducive to maintaining operators' SA [27-29]. Studies show that system safety risks mostly arise from human-computer interaction obstacles, which means errors should not solely be attributed to humans but also to display design $[10,30]$. Inappropriate display designs have been shown the potential to weaken an operator's SA and as a result increase the risk of human errors, especially in emergency situations [31]. Therefore, evaluating the utility of an interaction display for supporting an operator's $\mathrm{SA}$ in complex and abnormal situations is of particular importance [2,28,32]. An operator searches for information based on a specific task goal during execution, which requires that the exact information for decision-making should be visualized directly and accurately in a way that can be captured at first sight [29,33-35]. Endsley et al. [36] pointed out that one of the critical goals for display design should be to improve the operator's SA, which can effectively promote task performance and reduce human errors. Presently, a series of display design methods, including theoretical models and simulation methods, have been applied to support an operator's SA through optimizing the display content and display layout [37]. Considering the elements of display design, these models and theories point out that the merit of the display design features can be improved by optimizing the interface layout (e.g., rearranging the indicators' location, integration and clutter), enhancing indicators salience (e.g., size, color coding and highlighting border), as well as developing an interactive dashboard and decision-making support display [38-41]. Thus, there is a necessity to investigate the role of display design elements in influencing an operator's SA and performance in abnormal situations due to unexpected events.

Previous studies have pointed out that an operator's SA is vulnerable in abnormal or emergency situations, and as a general principle, display design is expected to provide support for maintaining SA [42-44]. However, facing abnormal situations, the SA construction process (e.g., attention resource transfer and reallocation) as well as construction result (e.g., behavioral performance and mental workload) have not been fully studied. Meanwhile, the inherent motivations, or the specific causes of capacity decline in cognition and operation, have not been clearly revealed, especially in flight scenarios. What is more, it is also especially necessary to examine whether the interaction displays usually designed 
based on routine environment can provide effective support in abnormal situations, and we are also interested in what kind of design features of the interaction display is more conducive to maintaining good flight performance, which may provide us with appropriate and feasible technical solutions in interface design [45,46]. Considering this, this study was aimed to examine the influence of air route alternation and display design on operators' SA, task performance and mental workload during simulated flight tasks, thus providing a basis for improving the measures or principles in optimizing both the standard operating procedures and display designs in response to abnormal situations. Furthermore, participants' eye movement measures were tracked as physiological indicators to reflect the attention allocation processes, as eye movement measures are believed to be related to SA and mental workload [45,47].

\section{Materials and Methods}

\subsection{Participants}

Recruiting participants on a voluntary basis from public universities has been a common practice in laboratory experiment research [28,29,41,42]. Twenty-four graduate students (15 males and 9 females) participated in our experiment, all from the School of Aeronautic Science and Engineering in Beihang University, and all with a good background in aviation and sufficient familiarity with simulated flight. Their mean age was 23.1 $(\mathrm{SD}=0.2)$ years. All participants were right-handed and had normal vision and hearing functions. No one had achromatopsia. Written informed consent was obtained from participants before the experiment.

\subsection{Apparatus}

Experimental tasks were implemented on a simulated flight platform (Figure 1), which was used to simulate the whole flight envelope, including taking off, climbing, cruising, approaching, and landing. The adopted simulated flight platform can be conducive to creating a realistic environment for the participants in our experiment $[39,43,47]$. Flight attitude data (speeds, altitudes, headings, etc.) could be recorded in real time in both automatic and manual operation modes. The platform also had a modular development function that was able to quickly simulate cockpit flight displays with high fidelity. The simulated cockpit flight displays included a primary flight display (PFD), a navigation display (ND), engine status displays and a control stand. The participants were seated in the left of the flight platform for flight control. A Tobii Pro X3-120 eye tracker was equipped on the flight platform to track and record the participants' eye movement data for the analysis of the participants' visual attention behavior during experimental tasks [44-50]. The sampling rate was $120 \mathrm{~Hz}$ and the binocular gaze accuracy was $0.5^{\circ}$. The eye tracker was placed in the middle near the bottom of the PFD and ND displays.

\subsection{Experimental Design}

The experiment implemented a two-factor $(2 \times 3)$ within-subjects design, with air route alternation and display design serving as independent variables. The two levels of the air route alternation included the air-route-as-planned condition and air-route-altered condition. Under the air-route-as-planned condition, participants were asked to keep the flight attitude parameters (including speed, altitude and course) according to the initial task plan, in which participants were required to make the speed and altitude reach the preset target values at all six observation time nodes $\left(T_{1} \sim T_{6}\right)$ and to keep the initial course unchanged (Figure 2). In the air-route-altered condition, participants were asked to execute a task plan that was the same as the one in the air-route-as-planned condition at the beginning. Afterwards, the plan changes would occur during the flight simulation, and the participants were required to make air route alternation according to the new situation, in which the target values of speed, altitude or course changed at all six observation time nodes (Figure 2). 

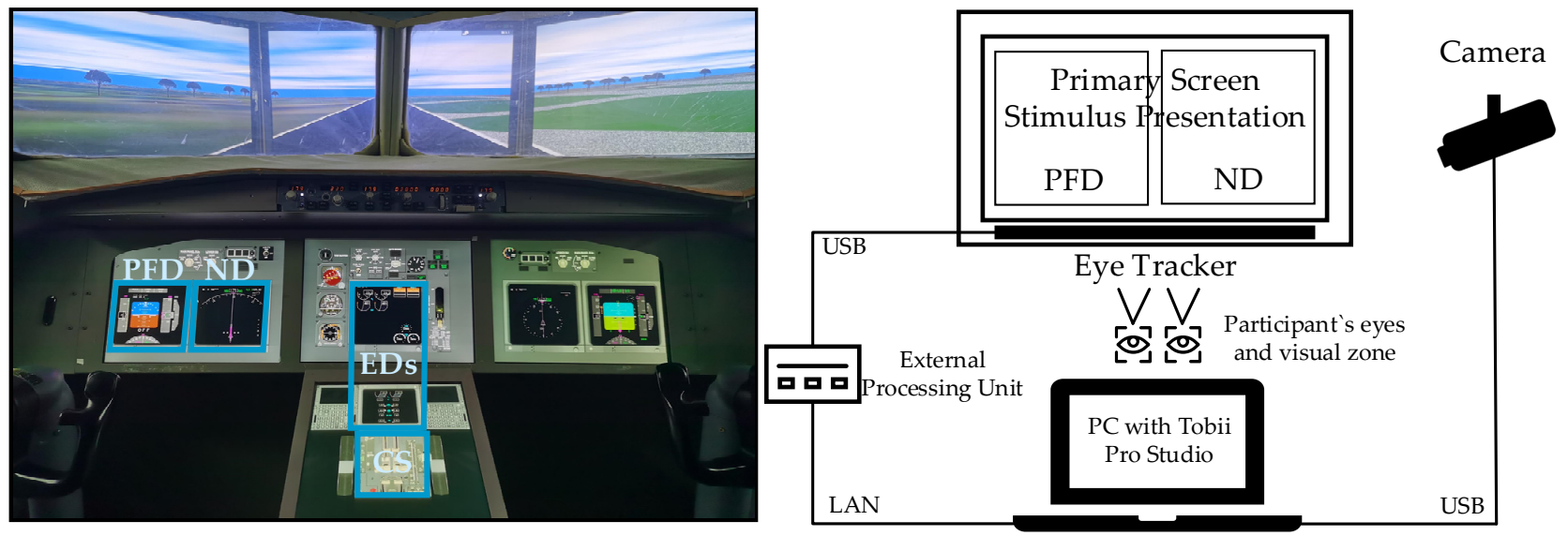

PFD: primary flight display; ND: navigation display; EDs: engine status displays; CS: control stand

Figure 1. Simulated flight platform (left) and eye tracker system (right).

Specifically, when the target course was changed, the participants were asked to turn the steering wheel in the correct direction (left or right) and to rotate horizontally until the new target course was reached. When the target speed was altered to a larger (or smaller) value, the participants were required to push forward (or pull back) the thrust levers and retract (or release) the flaps to accelerate (or decelerate). The participants were supposed to pull back or push forward the steering stick in a proper range to climb or descend to a new altered target altitude. Under the air-route-as-planned condition, the target course remained fixed; the target speed and altitude were set consistent with the task plan given before experimental task. The participants were supposed to mainly concentrate their visual attention on the PFD, excluding the ND, and to manipulate the handheld devices, excluding the steering wheel; thus, the eye-hand coordination was challenged at a lower level and the precision of task performance was of higher accessibility. Under the air-route-altered condition, all three flight attitude parameters were changed and different from the previously informed task plan. The participants were required to allocate their visual attention to both the PFD and ND, and to simultaneously manipulate all the handheld devices, leading to more challenges in eye-hand coordination and the precision of task performance.

The interface used in laboratory experiment research is usually extracted or simulated from actual scenarios [28,32,41], and different display designs of the flight parameters presented on the simulated flight platform also influence the participant's interactive behavior. In our experiment, three typical types of interface designs derived from civil aviation were examined, which varied mainly based on the design of the PFD, including Interface 1 (center-layout with a low-salience design, simulating an A320), Interface 2 (center-layout with a medium-salience design, simulating a B737) and Interface 3 (offcenter-layout with a high-salience design, simulating an ARJ-21). Obvious differences existed in the information layout and information visual coding among the three simulated interfaces. In Interface 1, the indicator of attitude (pitch and roll) was set in the center and the compass was of small size; also, the altitude was displayed in the open window digital indicator while the speed in the low-salience indicator was displayed without an open window design. In Interface 2, the information layout was similar to Interface 1, while digital displays of both the altitude and speed indicator were window designed. In Interface 3, the attitude indicator was set in the upper area and the compass was of full size, as well as the indicators of speed and altitude were both open window designed; moreover, the pitch information was not only displayed in the attitude indicator but also in both the speed and altitude indicators, with the horizon line separating the sky (blue color) and the ground (yellow color), which can provide a better immersive experience.

We drew four areas of interest (AoIs) for each of the three displays to examine the participants' visual attention. The AoIs were designed based on the task requirements in 
the simulated flight tasks, including the whole area of both PFD and ND (named as AoI 1), the speed indicator area (named as AoI 2), the altitude indicator area (named as AoI 3) and the course indicator area (named as AoI 4). All AoIs contained the necessary information for participants to control and adjust the flight attitude parameters.
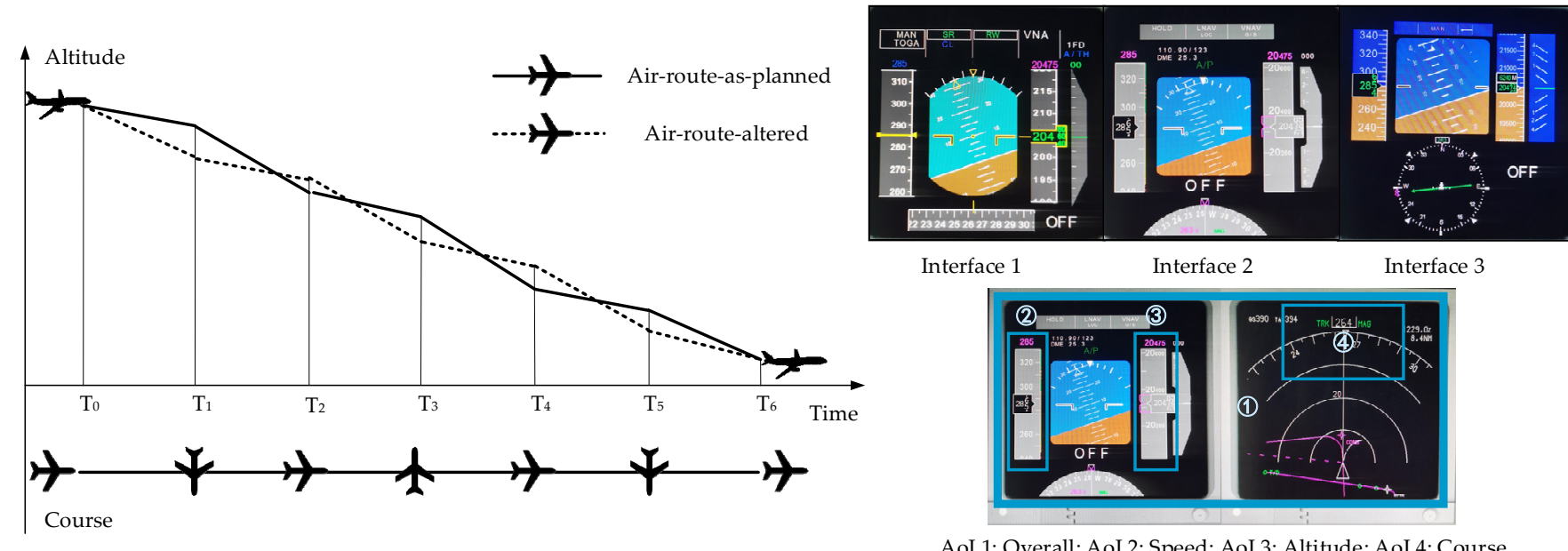

Figure 2. Experimental independent variables of air route alternation (left) and display design (right) with areas of interests (AoIs).

\subsection{Measurement}

Measurement in the present study included SA, task performance and mental workload. SA was assessed with two commonly used methods [51-55], including the threedimensional situation awareness rating technique (3D-SART) [56] and the situation present assessment technique (SPAM) [57]. 3D-SART is convenient to employ with good measurement validity [58], while SPAM is less invasive in high-fidelity task situations [59,60]. 3D-SART scale has three dimensions, including attention resource demand, attention resource supply and situation understanding. The 3D-SART score, calculated as the sum of the latter two dimensions, deducting the former one, was used to represent the SA levels. Moreover, we used the value of attention resource supply minus demand to assess the participants' attention resource surplus (ARS). The SPAM method was implemented with queries focused on the displayed range of parameters for altitude, speed, course, pitch, roll, thrust and flap, so that the participants' awareness on the current and future flight attitudes could be evaluated. SPAM response accuracy (RA) was recorded as the proportion of the participants' correct answers in all queries, and the SPAM response time (RT) was recorded as the average time interval from the queries' release to the time the participants answered the queries.

Task performance was assessed by operation accuracy, which was measured as the proportion of times that the participants successfully achieved the requirements in compliance with the plan or instruction. Mental workload was assessed with the National Aeronautics and Space Administration-Task Load Index (NASA-TLX), which consists of six dimensions, including mental demand, physical demand, temporal demand, performance, effort, and frustration [26]. A weighted sum of the six dimensions was computed as the mental workload. Furthermore, visual behavior of the participants was also assessed for analyzing the information perception and attention allocation, which have been verified associated with SA and mental workload. Two eye movement measures of the fixation rate and average pupil diameter were adopted [61-63]. Fixation rate was the ratio of fixation counts in an AoI to the total fixation counts, and the average pupil diameter was calculated as the average value of the pupil diameters of the participant's left and right eyes. 


\subsection{Tasks and Prodcedures}

As one of the basic flight tasks in aviation, flight attitude control was adopted as the experimental task in the present study, and participants were required to keep the values for altitudes, speeds and courses as required by the task plans or instructions, through manipulating the pitch, roll, thrust and flaps. Flight attitudes should be kept on or close to the target values within the given permissible error ranges (i.e., \pm 100 feet for altitude, \pm 10 knots for speed and \pm 2 degrees for course). Each participant was required to complete experimental tasks in six experimental conditions (i.e., combinations of two air route alternation conditions and three display design conditions), the order of which was counterbalanced among the participants. The participants had a 10-minute break after each experimental task. The flight control under all six experimental conditions was set to obey the same law of aerodynamics.

Before the experiment, all the participants attended a training session on the use of the simulated flight platform, read the flight plan and practiced manual control of the flight attitudes until proficient. Especially, the participants' synchronization capacity in controlling the course, speed and altitude was established through practicing simultaneous manipulation of the relevant handheld devices (e.g., thrust levers, flaps, steering stick and steering wheel). The participants were required to answer the SPAM queries as quickly and accurately as possible during the experimental tasks, and to fill in the subjective scales of 3D-SART and NASA-TLX at the end of each experimental task.

\subsection{Data Analysis}

Shapiro-Wilk's test was performed to verify whether the variables were normally distributed $(p>0.05)$. Two-way repeated measures analysis of variance (ANOVA) was used to examine the main and interaction effects of air route alteration and display design on SA, task performance and mental workload. Mauchly's test of sphericity was adopted to validate the ANOVAs. The Greenhouse-Geisser-adjusted freedom degree and $p$ value were used when the sphericity assumption was violated $(p<0.05)$. Post-hoc multiple comparisons were performed with Bonferroni adjustment if necessary. Level of significance was set at $\alpha=0.05$. Statistical analyses were performed with IBM SPSS Version 23 (Chicago, IL, USA).

\section{Results}

\subsection{Subjective Scales}

ANOVA results for 3D-SART are presented in Table 1. For the SA score of 3D-SART, the interaction effect between air route alternation and display design was significant $(\mathrm{F}(2,46)=3.755, p=0.031)$. The SA score in air-route-altered condition was significantly lower than that in the air-route-as-planned condition for Interface $1(\mathrm{~F}(1,23)=5.990$, $p=0.022)$ and Interface $3(\mathrm{~F}(1,23)=7.791, p=0.010)$. In terms of Interface 2 , no significant difference was observed in the SA score between the two air route alternation conditions $(p>0.05)$. Furthermore, for the ARS score, the interaction effect of air route alternation and display design was not significant $(p>0.05)$ while the main effect of air route was significant $(\mathrm{F}(1,23)=10.439, p=0.004)$. The ARS in air-route-altered condition was $79.54 \%$ lower than that in the air-route-as-planned condition.

There was a significant effect of air route alternation on mental workload $(\mathrm{F}(1,23)=17.210, p<0.001)$ (Table 1$)$. Mental workload in the air-route-altered condition was significantly higher than that in the air-route-as-planned condition. 
Table 1. ANOVA results for the subjective scale measures (mean (SD)).

\begin{tabular}{|c|c|c|c|c|c|c|c|c|c|c|}
\hline & \multicolumn{4}{|c|}{ Air Route Alternation } & \multicolumn{5}{|c|}{ Display Design } & \multirow{2}{*}{$\begin{array}{c}\text { Interaction } \\
p \text {-Value }\end{array}$} \\
\hline & $\begin{array}{c}\text { As } \\
\text { Planned }\end{array}$ & Altered & $p$-Value & ES & Interface 1 & Interface 2 & Interface 3 & $p$-Value & ES & \\
\hline 3D-SART (-) & & & & & & & & & & \\
\hline SA score & $\begin{array}{l}5.677 \\
(0.370)\end{array}$ & $\begin{array}{c}4.938 \\
(0.322)\end{array}$ & 0.018 & 0.222 & $5.563(0.312)$ & $5.188(0.346)$ & $5.156(0.344)$ & 0.065 & 0.112 & 0.031 * \\
\hline ARS & $\begin{array}{c}0.611 \\
(0.206)\end{array}$ & $\begin{array}{c}0.125 \\
(0.211)\end{array}$ & $0.004^{*}$ & 0.312 & $0.438(0.208)$ & $0.240(0.208)$ & $0.427(0.239)$ & 0.447 & 0.034 & 0.139 \\
\hline $\begin{array}{l}\text { NASA-TLX (-) } \\
\text { Workload }\end{array}$ & $\begin{array}{l}10.787 \\
(0.589)\end{array}$ & $\begin{array}{l}12.676 \\
(0.535)\end{array}$ & $<0.001^{* *}$ & 0.428 & $\begin{array}{l}11.827 \\
(0.552)\end{array}$ & $11.948(0.545)$ & $11.419(0.656)$ & 0.529 & 0.027 & 0.380 \\
\hline
\end{tabular}

Note: * Significant difference at the 0.05 level; ** Significant difference at the 0.001 level. Partial $\eta^{2}$ was used to calculate the effect size (ES) for the ANOVA results. ARS $=$ attention resource surplus.

\subsection{Behavioral Performance}

Table 2 presents the ANOVA results for SPAM response behavior. For RA, the interaction effect of air route alternation and display design had not been found significant $(p>0.05)$; The main effect of air route alternation was significant $(\mathrm{F}(1,23)=12.329$, $p=0.002)$, and RA in the air-route-altered condition was lower than that in the airroute-as-planned condition. For RT, a significant interaction effect was observed $(\mathrm{F}(1.508,30.169)=4.368, p=0.031)$.

Table 2. ANOVA results for the SPAM response behavior and task performance (mean (SD)).

\begin{tabular}{|c|c|c|c|c|c|c|c|c|c|c|}
\hline & \multicolumn{4}{|c|}{ Air Route Alternation } & \multicolumn{4}{|c|}{ Display Design } & \multicolumn{2}{|r|}{ Interaction } \\
\hline & $\begin{array}{c}\text { As } \\
\text { Planned }\end{array}$ & Altered & $p$-Value & ES & Interface 1 & Interface 2 & Interface 3 & $p$-Value & ES & $p$-Value \\
\hline \multicolumn{11}{|l|}{ SPAM } \\
\hline RA (-) & $\begin{array}{c}0.958 \\
(0.015)\end{array}$ & $\begin{array}{c}0.873 \\
(0.020)\end{array}$ & $00.002 *$ & 0.349 & $0.896(0.022)$ & $0.938(0.017)$ & $0.915(0.020)$ & 0.290 & 0.052 & 0.279 \\
\hline $\mathrm{RT}$ (ms) & $\begin{array}{l}2275 \\
(182)\end{array}$ & $\begin{array}{l}2269 \\
(156)\end{array}$ & 0.971 & 0.000 & $2554(267)$ & $2793(104)$ & 2168 (195) & 0.123 & 0.099 & $0.031 *$ \\
\hline \multicolumn{11}{|c|}{ Operation Accuracy (-) } \\
\hline Overall & $\begin{array}{c}0.975 \\
(0.008)\end{array}$ & $\begin{array}{c}0.672 \\
(0.019)\end{array}$ & $<0.001^{* *}$ & 0.881 & $0.836(0.013)$ & $0.842(0.010)$ & $0.791(0.017)$ & $0.013 *$ & 0.171 & 0.125 \\
\hline Altitude & $\begin{array}{c}0.963 \\
(0.017)\end{array}$ & $\begin{array}{c}0.700 \\
(0.044)\end{array}$ & $<0.001^{* *}$ & 0.526 & $0.847(0.026)$ & $0.863(0.027)$ & $0.785(0.024)$ & 0.014 * & 0.195 & 0.138 \\
\hline Speed & $\begin{array}{c}0.972 \\
(0.028)\end{array}$ & $\begin{array}{c}0.694 \\
(0.028)\end{array}$ & $<0.001^{* *}$ & 0.645 & $0.843(0.029)$ & $0.860(0.018)$ & $0.797(0.031)$ & 0.186 & 0.070 & 0.331 \\
\hline Course & $\begin{array}{l}10.000 \\
(0.000)\end{array}$ & $\begin{array}{c}0.825 \\
(0.031)\end{array}$ & $<0.001^{* *}$ & 0.585 & $0.914(0.021)$ & $0.929(0.023)$ & $0.896(0.020)$ & 0.450 & 0.034 & 0.450 \\
\hline
\end{tabular}

Note: * Significant difference at the 0.05 level; ${ }^{* *}$ Significant difference at the 0.001 level. Partial $\eta^{2}$ was used to calculate the effect size (ES) for the ANOVA results. $\mathrm{RA}=$ response accuracy; $\mathrm{RT}=$ response time.

ANOVA results for operation accuracy are presented in Table 2. For overall operation accuracy (involving all operations, such as speed, altitude and course), the interaction effect was not significant, while the main effects for both air route alternation $(\mathrm{F}(1,23)=169.542$, $p<0.001)$ and display design $(\mathrm{F}(2,46)=4.744, p=0.013)$ were significant. Compared with the overall operation accuracy in the air-route-as-planned condition, it declined in the air-route-altered condition. Besides, the overall operation accuracy in Interface 2 was higher than that in Interface 3.

In the further analysis of the various flight attitude parameters (i.e., altitude, speed and course), we can find that air route alternation $(\mathrm{F}(1,23)=25.520, p<0.001)$ and display design $(\mathrm{F}(1.464,33.663)=5.562, p=0.014)$ had significant main effects on altitude operation accuracy, while their interaction effect was not significant $(p>0.05)$. The altitude operation accuracy in the air-route-altered condition was lower than that in the air-route-as-planned condition, and it was higher in Interface 2 than that in Interface 3. Moreover, the air route yielded a significant main effect on both speed operation accuracy $(F(1,23)=41.812$, 
$p<0.001)$ and course operation accuracy $(\mathrm{F}(1,23)=32.360, p<0.001)$. The operation accuracy of both the speed and the course in the air-route-altered condition was lower than those in the air-route-as-planned condition.

\subsection{Eye Movement}

Table 3 presents the ANOVA results for fixation rate. No interaction effect $(p>0.05)$ between air route alternation and display design was found in terms of AoI 1 (Overall), AoI 2 (Speed) and AoI 3 (Altitude). For the fixation rate in AoI 1, 2 and 3, the main effect of air route was significant (AoI 1 (Overall): $\mathrm{F}(1,13)=108.727, p<0.001$; AoI 2 (Speed): $\mathrm{F}(1,13)=97.807, p<0.001$; AoI 3 (Altitude): $\mathrm{F}(1,13)=122.709, p<0.001)$, and the fixation rate of the three AoIs in the air-route-altered condition was $83.33 \%, 85.63 \%$ and $82.74 \%$ higher than those in air-route-as-planned condition, respectively. Furthermore, the main effect of display design on fixation rate in AoI 3 (Altitude) was also significant $(\mathrm{F}(2,26)=5.036, p=0.014)$, showing that the fixation rate for altitude area in Interface 2 is clearly decreased compared to Interface $3(p=0.009)$.

For the fixation rate in AoI 4 (Course), a significant interaction effect between air route and display design was observed $(\mathrm{F}(2,22)=4.324, p=0.026)$. In Interface 1,2 and 3, fixation rate in the air-route-altered condition, respectively, increased by $50.34 \%(\mathrm{~F}(1,14)=8.424$, $p=0.012), 100.78 \%(\mathrm{~F}(1,16)=74.807, p<0.001)$ and $48.41 \%(\mathrm{~F}(1,17)=14.646, p=0.001)$, compared with those in the air-route-as-planned condition. Meanwhile, a significant difference in display design was found in the air-route-altered condition, showing that the fixation rate in Interface 2 is increased compared to Interface $1(p=0.029)$.

There were significant main effects of air route alternation $(\mathrm{F}(1,19)=27.661, p<0.001)$ and display design $(\mathrm{F}(2,38)=14.005, p<0.001)$ on the average pupil diameter (Table 3$)$. Specifically, we found that the participants' average pupil diameter dilated in the air-routealtered condition compared to that in the air-route-as-planned condition. The average pupil diameters in Interface $2(p=0.001)$ and Interface $1(p=0.003)$ were also dilated compared to Interface 3.

Table 3. ANOVA results for the eye movement measures (mean (SD)).

\begin{tabular}{|c|c|c|c|c|c|c|c|c|c|c|}
\hline \multirow[b]{2}{*}{ AoIs } & \multicolumn{4}{|c|}{ Air Route Alternation } & \multicolumn{4}{|c|}{ Display Design } & \multicolumn{2}{|c|}{ Interaction } \\
\hline & $\underset{\text { Planned }}{\text { As }}$ & Altered & $p$-Value & ES & Interface 1 & Interface 2 & Interface 3 & $p$-Value & ES & $p$-Value \\
\hline \multicolumn{11}{|c|}{ Fixation rate (-) } \\
\hline Overall & $\begin{array}{c}0.180 \\
(0.020)\end{array}$ & $\begin{array}{c}0.339 \\
(0.034)\end{array}$ & $<0.001 * *$ & 0.893 & $0.246(0.031)$ & $0.260(0.027)$ & $0.273(0.030)$ & 0.371 & 0.073 & 0.736 \\
\hline Altitude & $\begin{array}{c}0.168 \\
(0.018)\end{array}$ & $\begin{array}{c}0.307 \\
(0.030)\end{array}$ & $<0.001 * *$ & 0.904 & $0.231(0.025)$ & $0.210(0.023)$ & $0.271(0.031)$ & $0.014 *$ & 0.279 & 0.360 \\
\hline Speed & $\begin{array}{c}0.160 \\
(0.021)\end{array}$ & $\begin{array}{c}0.297 \\
(0.031)\end{array}$ & $<0.001 * *$ & 0.883 & $0.207(0.031)$ & $0.216(0.028)$ & $0.217(0.037)$ & 0.258 & 0.099 & 0.306 \\
\hline Course & $\begin{array}{c}0.152 \\
(0.017)\end{array}$ & $\begin{array}{c}0.251 \\
(0.031)\end{array}$ & $0.001 *$ & 0.640 & $0.184(0.026)$ & $0.207(0.021)$ & $0.213(0.023)$ & 0.060 & 0.226 & $0.026^{*}$ \\
\hline \multicolumn{11}{|c|}{ Average pupil diameter $(\mathrm{mm})$} \\
\hline & $\begin{array}{l}40.300 \\
(0.109)\end{array}$ & $\begin{array}{l}40.529 \\
(0.113)\end{array}$ & $<0.001 * *$ & 0.593 & $40.432(0.108)$ & $40.502(0.112)$ & $40.309(0.113)$ & $<0.001^{* *}$ & 0.424 & 0.830 \\
\hline
\end{tabular}

Note: * Significant difference at the 0.05 level; ** Significant difference at the 0.001 level. Partial $\eta^{2}$ was used to calculate the effect size (ES) for the ANOVA results.

\section{Discussion}

Air route alternation in abnormal or emergency situations may affect operators' cognition and performance, and subsequently bring risks of human errors and accidents. Under such circumstances, it is also necessary to examine whether the interaction displays designed based on the routine environment can provide effective support for an operator's cognition and performance in an abnormal situation. In the present study, 24 participants were involved to perform simulated flight attitude control tasks, with the two conditions of air-route-as-planned and air-route-altered and three simulated display designs (centerlayout with a low-salience design for Interface 1, center-layout with a medium-salience design for Interface 2, and off-center-layout with a high-salience design for Interface 3). Data of the subjective scales, behavioral performances and eye movements of all the partic- 
ipants were collected to evaluate the effects of air route alternation and display design on an operator's SA, performance and mental workload.

\subsection{Effects of Air Route Alternation}

The results showed that compared with the air-route-as-planned condition, the score of the NASA-TLX scale and SPAM response accuracy under the air-route-altered condition was significantly decreased. Meanwhile, the SA scores of the 3D-SART were also observed as clearly reduced under the air-route-altered condition regarding Interfaces 1 and 3 (Figure 3a), indicating a notable decrease in the operator's SA when the air route changed suddenly. Further analysis about the dimensions of the 3D-SART scale showed that the ARS under the air-route-altered condition declined $79.54 \%$ on average compared to that under the air-route-as-planned condition (Figure $3 \mathrm{~b}$ ). These findings could also be verified from the eye movement data, as the fixation rate in all the AoIs and the average pupil diameter increased dramatically under the air-route-altered condition compared to the air-route-as-planned condition, suggesting that the unplanned air route alternation led to a higher demand of attention resource.

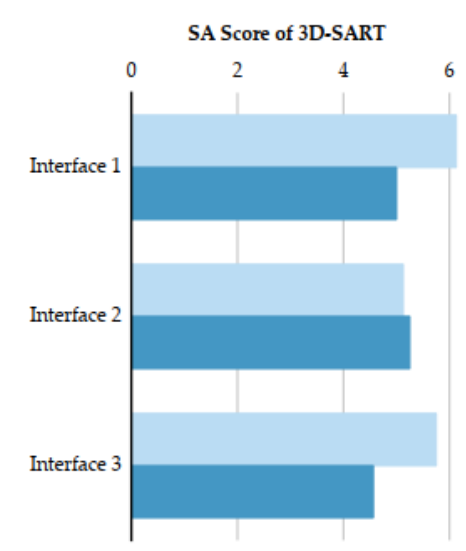

(a) SA score of 3D-SART

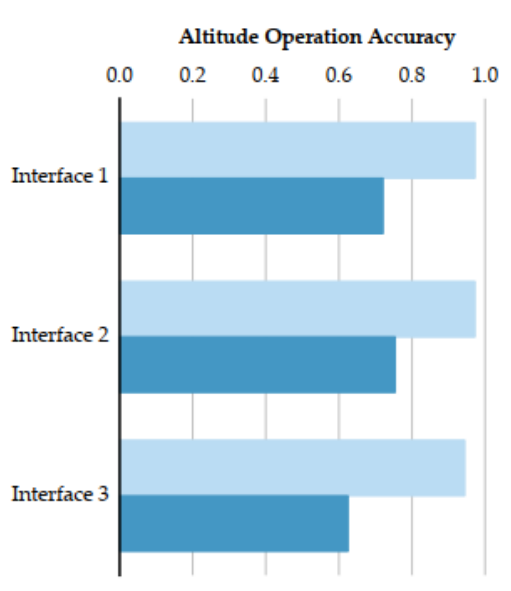

(d) Altitude operation accuracy

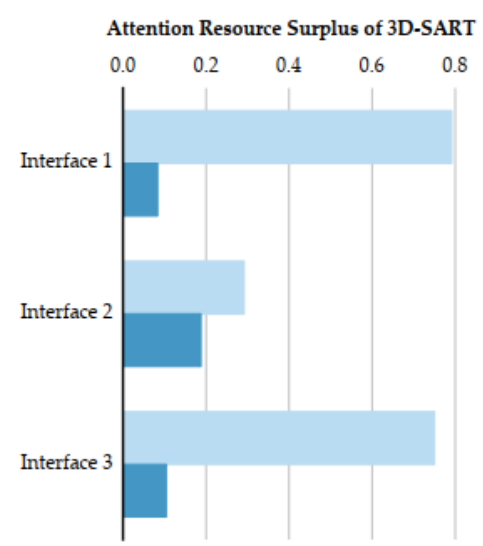

(b) Attention resource surplus (ARS) of 3D-SART

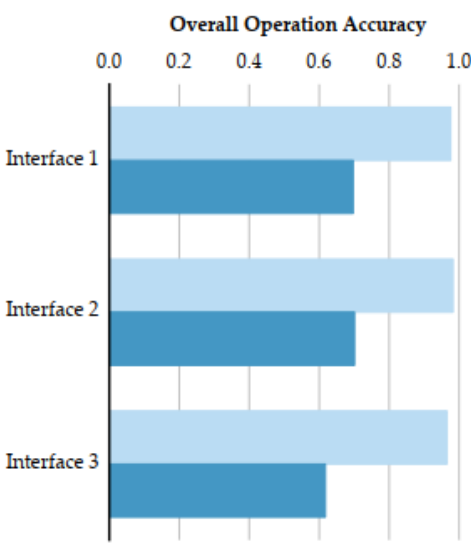

(c) Overall operation accuracy

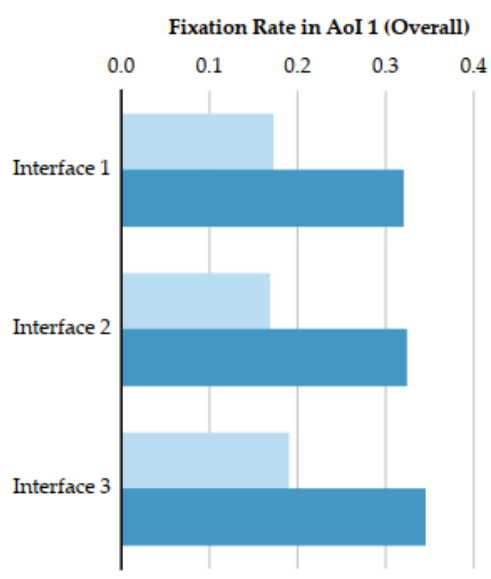

(e) Fixation rate in AoI 1 (Overall)

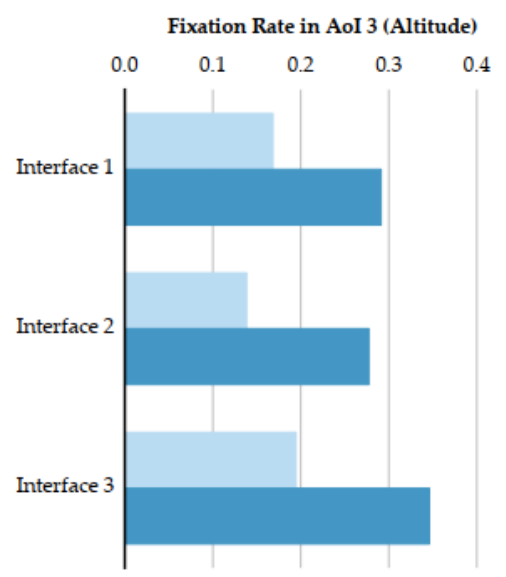

(f)Fixation rate in $\mathrm{AoI} 3$ (Altitude) Air-route-as-planned Air-route-altered

Figure 3. Measurement indices in different display designs under conditions of air-route-as-planned and air-route-altered. (a) SA score of 3D-SART; (b) Attention resource surplus (ARS) of 3D-SART; (c) Overall operation accuracy; (d) Altitude operation accuracy; (e) Fixation rate in AoI 1 (Overall); (f) Fixation rate in AoI 3 (Altitude). 
Previous studies show that the deterioration in SA can be caused by an increase in task complexity $[8,60]$. In the current study, the complexity of the flight attitude control task is varied by the unplanned air route alternation, and the SA degradation under the airroute-altered condition can be attributed to the fact that operators needed to consume more attention resources to cope with the comprehension and decision-making in the unplanned air route alternation situation, which results in the intensified imbalance between attention resource demand and supply. Some studies reported that a feasible approach to improve operators' SA in abnormal situations is to relieve the demand of cognitive resources for decision-making, such as adding planning aids, providing explanations or direct solutions by the system $[18,24,25]$. In terms of task performance, similarly, the deterioration in operation accuracy is initiated by the unexpected air route alternation, whether for the overall operation accuracy or a specific flight attitude parameter (i.e., altitude, speed and course). This is consistent with the findings of some previous literature, suggesting the decline in performance is usually caused by a degradation in SA [63-65]. The variation in performance can be used as one of the criteria to assess an operator's SA, and their performance can be promoted by an enhancement in SA.

\subsection{Effects of Display Design}

As for different display designs, despite the fact that a reduction in ARS under the air-route-altered condition can be observed in all three display designs, the difference in the 3D-SART scores between the two conditions of air-route-as-planned and air-route-altered was not significant for Interface 2 (center-layout with a medium-salience design), while being significant for Interface 1 (center-layout with a low-salience design) and Interface 3 (off-center layout with a high-salience design). Moreover, the overall operation accuracy and altitude operation accuracy in Interface 2 were also significantly higher than those in Interface 3 (Figure 3c,d), and no differences were found between Interface 1 and 2, nor between Interface 1 and 3 . The results of the 3D-SART scores and operational performances suggest that, compared with Interfaces 1 and 3, the design of Interface 2 is more conducive to the maintenance of an operator's SA and flight performance in abnormal or emergency situations [66-68]. In addition, compared with Interface 3, the increase in average pupil diameter in Interface 2 suggests that the participants paid higher attention during the task completion $[69,70]$.

Considering the promoting effect of salience design on SA, the significant difference between Interfaces 2 and 3 suggests that, compared with an off-center-layout design, a central-layout design is beneficial for operators' rapid and accurate capture of the critical decision-making information (such as altitude, manifesting as the decreased fixation rate of altitude AoI in Interface 2), which contributes to operators' good SA and the stability of overall performance in situations of unexpected changes or events [29,62,63]. Furthermore, the significant difference between Interfaces 2 and 3 also indicates that the factor of information layout design has a far greater impact on SA and task performance than the factor of salience design in our study. Another point worth noting is that the high-salience design of open-window-designed digital indicators and more immersive pitch attitude design can neutralize the adverse effect of an off-center-layout design on an operator's SA and task performance to a certain extent, which results in the nonsignificant differences between Interfaces 1 and 3. Related studies have pointed out that an SA-oriented display design, such as a high-salience design (focusing on the improvement of information perception and visual attention), is able to play a critical role in facilitating the function of the interaction display and promoting the comprehensive efficiency of human-machine systems $[51,63,66,71]$. The experimental results of the present study demonstrate that good display designs, such as adopting a center-layout design for the critical decision-making information and using a high-salience design, are helpful to maintaining an operator's SA in dynamic, abnormal and unplanned situations. 


\subsection{Limitations and Future Works}

There are still several limitations in the present study. Firstly, preliminary laboratory research was implemented to investigate the effect of air route alternation and display design on an operator's SA, performance and mental workload during simulated flight tasks. The participants adopted in our study were not pilots but graduate students from an aeronautical science and engineering department with experience in operating the simulated flight platform. Considering the participants' ability and experience, we simplified the flight task and extracted the basic and essential operation (i.e., flight attitude control) as experimental tasks. The participants also received adequate training with appropriate standards to ensure they were competent and qualified for the experiment. Although the reference value of this prophase exploratory research can benefit from the above efforts, experienced pilots, as well as flight scenarios with higher fidelity and complexity (e.g., taxi route crossing, flight fault, air route alternation in severe meteorological condition, etc.) will be considered in future work to improve the reliability and richness of the research conclusion. Secondly, although we have examined the applicability of display designs to support an operator's SA and performance in the condition of air route alternation, the display interfaces tested in our study belonged to relatively traditional mainstream designs, owing to the function limitations of the current simulated flight platform. As a next step, the simulated display designs should be further developed and advanced concepts (e.g., head-up display, enhanced visual display, synthetic visual display, etc.) should be incorporated to evaluate the display utility in abnormal situations due to unplanned events [72].

\section{Conclusions}

Considering the challenges of abnormal flight situations to the utility of an interface as well as a human's capacity in cognition and behavior, the present study investigated the effects of air route alternation and display design on operators' SA, task performance and mental workload. The vulnerability of a human's capacity in cognition and behavior under abnormal situations can be explained from the perspective of balancing and maintaining attention supply and demand. An increase in an operator's mental workload as well as the degradation of their SA and task performance can be attributed to the intensified imbalance between attention resource demand and supply caused by unexpected air route alternation. The strategies to cope with abnormal situations can be focused on reducing the demand of an operator's attention resource through optimizing the task design or offering planning aids. In addition, the robustness of a human's capacity in cognition and behavior can be improved through optimizing the interface design elements, such as information layout and salience. Reasonable information layout, such as the center-layout design of the critical decision-making information, shows more importance than information salience for improving the SA and task performance in abnormal situations. Nevertheless, indicators with a high-salience design, such as open window and immersive designs, are still worthy options for maintaining an operator's SA and task performance in abnormal situations due to unexpected events.

Author Contributions: Conceptualization, H.C. and X.W.; methodology, H.C.; validation, L.P., S.L. and D.T.; formal analysis, H.C.; investigation, H.C. and L.P.; resources, H.C. and X.W.; data curation, H.C.; writing — original draft preparation, H.C.; writing—review and editing, X.W., S.L. and D.T.; visualization, H.C.; supervision, Y.F.; project administration, X.W.; funding acquisition, X.W. All authors have read and agreed to the published version of the manuscript.

Funding: This study was co-supported by the National Natural Science Foundation of China (No. 71301005) and the joint program of the National Natural Science Foundation of China and Civil Aviation Administration of China (No. U1733118), as well as the Aeronautical Science Foundation of China (No. 201813300002).

Informed Consent Statement: Written informed consent was obtained from all participants involved in the study to publish this paper. 
Conflicts of Interest: The authors declare no conflict of interest.

\section{References}

1. Endsley, M.R.; Sollenberger, R.; Stein, E. Situation awareness: A comparison of measures. In Proceedings of the Human Performance, Situation Awareness and Automation: User-Centered Design for the New Millennium, Savannah, GA, USA, 16-19 October 2000.

2. Stanton, N.A.; Salmon, P.M.; Walker, G.H.; Salas, E.; Hancock, P.A. State-of-science: Situation awareness in individuals, teams and systems. Ergonomics 2017, 60, 449-466. [CrossRef]

3. Flin, R.H.; O'connor, P.; Crichton, M. Safety at the Sharp End: A Guide to Non-Technical Skills; Ashgate: Farnham, UK, 2008.

4. Sætrevik, B.; Hystad, S.W. Situation awareness as a determinant for unsafe actions and subjective risk assessment on offshore attendant vessels. Saf. Sci. 2017, 93, 214-221. [CrossRef]

5. Stanton, N.A.; Chambers, P.R.G.; Piggott, J. Situational awareness and safety. Saf. Sci. 2001, 39, 189-204. [CrossRef]

6. Endsley, M.R. Errors in situation assessment: Implications for system design. In Human Error and System Design and Management; Springer: Cham, Switzerland, 2000; pp. 15-26.

7. Vanderhaegen, F.; Wolff, M.; Mollard, R. Non-conscious errors in the control of dynamic events synchronized with heartbeats: A new challenge for human reliability study. Saf. Sci. 2020, 129, 11. [CrossRef]

8. Golestani, N.; Abbassi, R.; Garaniya, V.; Asadnia, M.; Khan, F.I. Human reliability assessment for complex physical operations in harsh operating conditions. Process Saf. Environ. Prot. 2020, 140, 1-13. [CrossRef]

9. Cak, S.; Say, B.; Misirlisoy, M. Effects of working memory, attention, and expertise on pilots' situation awareness. Cogn. Technol. Work 2020, 22, 85-94. [CrossRef]

10. Salmon, P.M.; Walker, G.H.; Stanton, N.A. Pilot error versus sociotechnical systems failure: A distributed situation awareness analysis of Air France 447. Theor. Issues Ergon. Sci. 2016, 17, 64-79. [CrossRef]

11. David, L.Z.; Schraagen, J.M. Analysing communication dynamics at the transaction level: The case of Air France Flight 447. Cogn. Technol. Work 2018, 20, 637-649. [CrossRef]

12. Papadimitriou, E.; Schneider, C.; Tello, J.A.; Damen, W.; Vrouenraets, M.L.; Ten Broeke, A. Transport safety and human factors in the era of automation: What can transport modes learn from each other? Accid. Anal. Prev. 2020, 144, 105656. [CrossRef]

13. Hai, V.P.; Moore, P. Emergency service provision using a novel hybrid som-spiral stc model for group decision support under dynamic uncertainty. Appl. Sci. 2019, 9, 3910.

14. Fertier, A.; Barthe-Delanoë, A.-M.; Montarnal, A.; Truptil, S.; Bénaben, F. A new emergency decision support system: The automatic interpretation and contextualisation of events to model a crisis situation in real-time. Decis. Support Syst. 2020, 133, 113260. [CrossRef]

15. Seppänen, H.; Mäkelä, J.; Luokkala, P.; Virrantaus, K. Developing shared situational awareness for emergency management. Saf. Sci. 2013, 55, 1-9. [CrossRef]

16. Minotra, D.; Mcneese, M.D. Predictive aids can lead to sustained attention decrements in the detection of non-routine critical events in event monitoring. Cogn. Technol. Work 2017, 19, 161-177. [CrossRef]

17. Asmayawati, S.; Nixon, J. Modelling and supporting flight crew decision-making during aircraft engine malfunctions: Developing design recommendations from cognitive work analysis. Appl. Ergon. 2020, 82, 12. [CrossRef]

18. Baethge, A.; Rigotti, T. Interruptions to air route: Their relationship with irritation and satisfaction with performance, and the mediating roles of time pressure and mental demands. Work Stress 2013, 27, 43-63. [CrossRef]

19. Lee, J.; Marla, L.; Jacquillat, A. Dynamic Disruption Management in Airline Networks Under Airport Operating Uncertainty. Transp. Sci. 2020, 54, 973-997.

20. Weigl, M.; Catchpole, K.; Wehler, M.; Schneider, A. Air route disruptions and provider situation awareness in acute care: An observational study with emergency department physicians and nurses. Appl. Ergon. 2020, 88, 9. [CrossRef]

21. Bukowski, J.H.; Richards, J.R. Commercial Airline In-Flight Emergency: Medical Student Response and Review of Medicolegal Issues. J. Emerg. Med. 2016, 50, 74-78. [CrossRef] [PubMed]

22. Martin-Gill, C.; Doyle, T.J.; Yealy, D.M. In-Flight Medical Emergencies A Review. JAMA J. Am. Med. Assoc. 2018, 320, 2580-2590. [CrossRef] [PubMed]

23. De Caprariis, P.J.; De Caprariis-Salerno, A.; Lyon, C. Healthcare Professionals and In-Flight Medical Emergencies: Resources, Responsibilities, Goals, and Legalities as a Good Samaritan. South. Med. J. 2019, 112, 60-65. [CrossRef]

24. Pritchett, A.R.; Ockerman, J.J. Supporting mixed-initiative emergency flight planning by portraying procedure context information. Cogn. Technol. Work 2016, 18, 643-655. [CrossRef]

25. Sene, A.; Kamsu-Foguem, B.; Rumeau, P. Decision support system for in-flight emergency events. Cogn. Technol. Work 2018, 20, 245-266. [CrossRef]

26. Young, M.S.; Brookhuis, K.A.; Wickens, C.D.; Hancock, P.A. State of science: Mental workload in ergonomics. Ergonomics 2015, 58, 1-17. [CrossRef]

27. Ackerman, R.K. Army intelligence digitizes situational awareness. Signal 2005, 59, 23.

28. Wei, H.; Zhuang, D.; Wanyan, X.; Wang, Q. An experimental analysis of situation awareness for cockpit display interface evaluation based on flight simulation. Chin. J. Aeronaut. 2013, 26, 884-889. [CrossRef] 
29. Zhang, X.; Qu, X.; Xue, H.; Tao, D.; Li, T. Effects of time of day and taxi route complexity on navigation errors: An experimental study. Accid. Anal. Prev. 2019, 125, 14-19. [CrossRef] [PubMed]

30. Nadj, M.; Maedche, A. Situation Awareness in Aircraft Ground Handling: The Impact of Auditory and Visual Notification Cues. J. Cogn. Eng. Decis. Mak. 2019, 13, 102-122. [CrossRef]

31. Stanton, N.A.; Stewart, R.; Harris, D.; Houghton, R.J. Distributed situation awareness in dynamic systems: Theoretical development and application of an ergonomics methodology. Ergonomics 2006, 49, 1288-1311. [CrossRef]

32. Burns, C.M.; Skraaning, G.; Jamieson, G.A.; Lau, N.K.C. Evaluation of Ecological Interface Design for Nuclear Process Control: Situation Awareness Effects. Hum. Factors 2008, 50, 663-679. [CrossRef]

33. Wickens, C.D. Situation Awareness: Review of Mica Endsley's 1995 Articles on Situation Awareness Theory and Measurement. Hum. Factors 2008, 50, 397-403. [CrossRef]

34. Endsley, M.R. Designing for Situation Awareness: An Approach to User-Centered Design; CRC Press: Boca Raton, FL, USA, 2016.

35. Bolstad, C.; Costello, A.; Endsley, M. Bad situation Awareness Designs: What Went Wrong and Why. In Proceedings of the International Ergonomics Association (IEA) 16th World Congress, Maastricht, The Netherlands, 7 July 2006.

36. Lurie, N.H.; Mason, C.H. Visual Representation: Implications for Decision Making. J. Mark. 2007, 71, 160-177. [CrossRef]

37. Endsley, M.R.; Connors, E.S. Situation awareness: State of the art. In Proceedings of the 2008 IEEE Power and Energy Society General Meeting-Conversion and Delivery of Electrical Energy in the 21st Century, Pittsburgh, PA, USA, 20-24 July 2008; pp. 1-4.

38. Schneiders, C.; Vanzetta, J.; Verstege, J.F. Enhancement of situation awareness in wide area transmission systems for electricity and visualization of the global system state. In Proceedings of the 2012 3rd IEEE PES Innovative Smart Grid Technologies Europe (ISGT Europe), Berlin, Germany, 14-17 October 2012; pp. 1-9.

39. Naderpour, M.; Lu, J. A Human Situation Awareness Support System to Avoid Technological Disasters. Decis. Aid Model. Disaster Manag. Emerg. 2013, 307-325. [CrossRef]

40. Ackerman, K.A.; Talleur, D.A.; Carbonari, R.S.; Xargay, E.; Seefeldt, B.D.; Kirlik, A.; Hovakimyan, N.; Trujillo, A.C. Automation Situation Awareness Display for a Flight Envelope Protection System. J. Guid. Control Dyn. 2017, 40, 964-980. [CrossRef]

41. Deng, L.; Wang, G.; Yu, S. Layout Design of Human-Machine Interaction Interface of Cabin Based on Cognitive Ergonomics and GA-ACA. Comput. Intell. Neurosci. 2016, 2016, 1032139. [CrossRef]

42. Chen, Y.; Gao, Q.; Song, F.; Li, Z.; Wang, Y. Procedure and information displays in advanced nuclear control rooms: Experimental evaluation of an integrated design. Ergonomics 2017, 60, 1158-1172. [CrossRef] [PubMed]

43. Foulsham, T.; Cheng, J.T.; Tracy, J.L.; Henrich, J.; Kingstone, A. Gaze allocation in a dynamic situation: Effects of social status and speaking. Cognition 2010, 117, 319-331. [CrossRef] [PubMed]

44. Behrend, J.; Dehais, F. How role assignment impacts decision-making in high-risk environments: Evidence from eye-tracking in aviation. Saf. Sci. 2020, 127, 104738. [CrossRef]

45. Lu, Y.Y.; Zheng, Y.Y.; Wang, Z.; Fu, S. Pilots' Visual Scanning Behaviors During an Instrument Landing System Approach. Aerosp. Med. Hum. Perform. 2020, 91, 511-517. [CrossRef]

46. Lounis, C.; Peysakhovich, V.; Causse, M. Flight Eye Tracking Assistant (FETA): Proof of Concept. In Advances in Human Factors of Transportation, Proceedings of the AHFE 2019 International Conference on Human Factors in Transportation, Washington, DC, USA, 24-28 July 2019; Springer: Cham, Switzerland, 2020; pp. 739-751.

47. Wanyan, X.R.; Zhuang, D.M.; Wei, H.Y.; Song, J. Pilot attention allocation model based on fuzzy theory. Comput. Math. Appl. 2011, 62, 2727-2735. [CrossRef]

48. She, M.; Li, Z.; Ma, L. User-defined information sharing for team situation awareness and teamwork. Ergonomics 2019, 62, 1098-1112. [CrossRef]

49. Sherry, L.; Donnelly, O.S. Design of a Display for Alerting Cockpit Automation Function Configuration Changes. In Proceedings of the 2019 Integrated Communications, Navigation and Surveillance Conference (ICNS), Herndon, VA, USA, 9-11 April 2019.

50. Zahabi, M.; Kaber, D. Effect of police mobile computer terminal interface design on officer driving distraction-ScienceDirect. Appl. Ergon. 2018, 67, 26-38. [CrossRef] [PubMed]

51. Mosaly, P.R.; Adams, R.; Tracton, G.; Dooley, J.; Adapa, K.; Nuamah, J.K.; Marks, L.B.; Mazur, L.M. Impact of Workspace Design on Radiation Therapist Technicians' Physical Stressors, Mental Workload, Situation Awareness and Performance. Pract. Radiat. Oncol. 2021, 11, e3-e10. [CrossRef] [PubMed]

52. Argyle, E.M.; Gourley, J.J.; Kang, Z.; Shehab, R.L. Investigating the relationship between eye movements and situation awareness in weather forecasting. Appl. Ergon. 2020, 85, 103071. [CrossRef]

53. Kirkwood, M. Designing for Situation Awareness in the Main Control Room of a Small Modular Reactor. Proc. Hum. Factors Ergon. Soc. Ann. Meet. 2019, 63, 2185-2189. [CrossRef]

54. Wanyan, X.; Zhuang, D.; Lin, Y.; Xiao, X.; Song, J.-W. Influence of mental workload on detecting information varieties revealed by mismatch negativity during flight simulation. Int. J. Ind. Ergon. 2018, 64, 1-7. [CrossRef]

55. Lu, T.J.; Lou, Z.S.; Shao, F.; You, M. Attention allocation in pilots based on climbing and circling mission behavior. Psychol. Res. 2021, 85, 1136-1145. [CrossRef]

56. Taylor, R.M. Situational awareness rating technique (SART): The development of a tool for aircrew systems design. In Situational Awareness; Routledge: London, UK, 2017; pp. 111-128. 
57. Endsley, M.R. A Systematic Review and Meta-Analysis of Direct Objective Measures of Situation Awareness: A Comparison of SAGAT and SPAM. Hum. Factors 2019, 63, 124-150. [CrossRef]

58. Jeannot, E. Situation Awareness Synthesis and Literature Search (EEC Note No. 16/00); Eurocontrol Experimental Centre: Bretigny-surOrge, France, 2000.

59. Friedrich, M.; Biermann, M.; Gontar, P.; Biella, M.; Bengler, K. The influence of task load on situation awareness and control strategy in the ATC tower environment. Cogn. Technol. Work 2018, 20, 205-217. [CrossRef]

60. Salmon, P.M.; Stanton, N.A.; Walker, G.H.; Jenkins, D.; Ladva, D.; Rafferty, L.; Young, M. Measuring Situation Awareness in complex systems: Comparison of measures study. Int. J. Ind. Ergon. 2009, 39, 490-500. [CrossRef]

61. Wei, Z.; Zhuang, D.; Wanyan, X.; Liu, C.; Zhuang, H. A model for discrimination and prediction of mental workload of aircraft cockpit display interface. Chin. J. Aeronaut. 2014, 27, 1070-1077. [CrossRef]

62. Li, G.F.; Wang, Y.; Zhu, F.P.; Sui, X.; Wang, N.; Qu, X.; Green, P. Drivers' visual scanning behavior at signalized and unsignalized intersections: A naturalistic driving study in China. J. Saf. Res. 2019, 71, 219-229. [CrossRef]

63. Nadj, M.; Maedche, A.; Schieder, C. The effect of interactive analytical dashboard features on situation awareness and task performance. Decis. Support Syst. 2020, 135, 13. [CrossRef] [PubMed]

64. Van Doorn, E.; Horvath, I.; Rusak, Z. Effects of coherent, integrated, and context-dependent adaptable user interfaces on operators' situation awareness, performance, and workload. Cogn. Technol. Work 2020. [CrossRef]

65. Van Der Kleij, R.; Hueting, T.; Schraagen, J.M. Change detection support for supervisory controllers of highly automated systems: Effects on performance, mental workload, and recovery of situation awareness following interruptions. Int. J. Ind. Ergon. 2018, 66, 75-84. [CrossRef]

66. Wickens, C.D. Display Formatting and Situation Awareness Model (DFSAM): An Approach to Aviation Display Design; Aviation Human Factors Division: Moffat Field, CA, USA, 2005.

67. Lau, N.; Jamieson, G.A.; Skraaning, G., Jr. Empirical evaluation of the Process Overview Measure for assessing situation awareness in process plants. Ergonomics 2016, 59, 393-408. [CrossRef]

68. Li, W.C.; Zakarija, M.; Yu, C.S.; McCarty, P. Interface design on cabin pressurization system affecting pilot's situation awareness: The comparison between digital displays and pointed displays. Hum. Factors Ergon. Manuf. Serv. Ind. 2019, 30, 103-113. [CrossRef]

69. Morando, A.; Victor, T.; Dozza, M. A Reference Model for Driver Attention in Automation: Glance Behavior Changes During Lateral and Longitudinal Assistance. IEEE Trans. Intell. Transp. Syst. 2019, 20, 2999-3009. [CrossRef]

70. Zhang, L.; Zhuang, D.M.; Wanyan, X.R. Information Coding for Cockpit Human-machine Interface. Chin. J. Mech. Eng. 2011, 24, 707-712. [CrossRef]

71. Durso, F.T.; Hackworth, C.A.; Truitt, T.R.; Crutchfield, J.; Nikolić, D. Situation awareness as a predictor of performance for en route air traffic controllers. Air Traffic Control Q. 1998, 6, 1-20. [CrossRef]

72. Almeida, L.; Menezes, P.; Dias, J.M. Interface transparency issues in teleoperation. Appl. Sci. 2020, 10, 6232. [CrossRef] 